\title{
Managing organizational change by Using soft systems thinking in action research projects
}

Shankar Sankaran

Faculty of Design Architecture and Building, University of Technology Sydney, Australia

Tay Boon Hou

Artificial Intelligence Laboratory, IN Technology Pte Ltd, Singapore

Martin Orr

Director, Information Services, Waitemata District Hospital, Auckland, New Zealand

Corresponding author email: Shankar.Sankaran@uts.edu.au

Submitted July $3^{\text {rd }} 2008$, Accepted October $15^{\text {th }} 2008$

\section{Abstract \\ Purpose}

This paper shows how systems thinking can be incorporated in action research interventions to successfully implement organizational change. The two case studies described in this paper would be useful to managers who want to implement change in their own organizations.

\section{Design/methodology/approach}

Both projects used action research as the methodology due to its flexible, responsive and emergent nature. In one project, there was a deliberate attempt to incorporate soft systems thinking whereas in the other project soft systems thinking was used as a sense-making process while carrying out action research. As an added benefit both approaches have resulted in successful completion of doctoral research.

\section{Findings}

Soft systems methodology (SSM) and action research (AR) can both help in addressing illstructured problems faced by managers, in collaboration with stakeholders using questioning and reflection. Both lead to an increased understanding about the problem situation. The difference is that SSM uses a more structured approach while AR is emergent in its application. SSM practitioners advocate that action researchers would benefit by declaring in advance an intellectual framework to guide their research. This has the additional benefit of overcoming obstacles in an academic environment where research processes are still governed based on traditional research methods.

\section{Practical implications}

The ideas presented in the paper could be particularly useful to a practice-based discipline such as project management where research into its practice is in demand.

\section{Originality/value}

This paper would be useful to managers interested in a rigorous methodology to implement organizational change in addressing business problems. It demonstrates ways of combining SSM and AR, resulting in a powerful research tool to carry out rigorous research. 


\section{Category}

Research paper

Keywords: Systems Thinking, Action Research, Soft Systems Methodology, Organizational Change, Management Research.

\section{Introduction}

While doctoral programs were traditionally pursued by academics or practitioners wanting to build a career in academia there has been a recent increase in the number of managers wanting to pursue doctoral research. Many of these managers have not followed the normal research pathway i.e. doing an honours degree along with their Bachelor's degrees which is the requirement for admission into a doctoral program in Australian Universities.

Many Australian universities are now offering Professional Doctorates, such as the Doctor of Business Administration (DBA) or Doctor of Project Management (DPM) programs, for which the pre-requisite qualification is a Master of Business Administration or a Master of Project Management where the practitioner may not have studied research courses. Therefore, professional doctorates which combine coursework with a thesis (or dissertation) also teach research methodologies so that candidates can design a suitable methodology for their studies.

In the university where the research projects described in this paper were carried out, most managers initially learnt standard research methodologies taught in universities, such as quantitative and qualitative methods. As the courses developed, it was felt that there were advantages in teaching methodologies or approaches such as case studies and action research (AR) which would be useful to managers who wanted to conduct research in their workplace. This had the benefit of managers being able to apply findings from the research to their practice. It also helped in simplifying the process required to collect data as it could be done in-house.

One of the research projects described in this paper is from the university's DBA program. The other project is from a special $\mathrm{PhD}$ program set up by the university in Singapore where the researchers were expected to use AR as their methodology as the university was positioning itself as a centre for excellence in AR (Sankaran et al. 2006). These two projects were selected for this paper as they incorporated SSM in different ways into AR. The principal author of this paper was involved in the supervision of the two researchers whose projects have been used as case studies in this paper.

The authors of this paper feel that sharing their experiences in conducting AR would help other managers who plan to use AR to solve real problems in their workplace. The authors have a background or responsibility in developing systems for information, software development or knowledge management in their present or past careers. Hence they had an interest in finding ways to use systems thinking in their research as well. They feel that using systems thinking, especially soft systems thinking, need not be limited to people involved with information or 
communication systems. This approach is useful for understanding any system—particularly those systems that involve human activities which lead to complexity and result in multiple perspectives of how a problem is viewed.

Using AR approaches could be practical and useful to project managers who want to do research in their own organizations or projects. A recent UK government funded research project (Cicimil et al. 2006) has suggested that there should be more research into the practice of project management by studying how project managers actually deal with the problems they face in their work. AR is mentioned as one of the methodologies that would be useful to conduct such research.

\section{Review of methodological literature}

A brief review of essential aspects of AR and soft systems methodology (SSM) is carried out in the next two sections of this paper for readers to understand how they were applied in the research projects that are later described. AR became prominent as a research approach in the 1940s when it was used to address social problems by Kurt Lewin (1946). The review of AR in this paper is confined to its use in management research, and specifically to the way in which the university where these research projects were conducted used it. The review of the literature associated with SSM covers its beginnings in Lancaster University in the 1970s to the three important stages in its development. A version of SSM suitable for use with AR developed in Australia is also explained. The review also discusses views expressed by scholars and practitioners about the relationship between systems thinking and AR.

\section{Action research}

AR is generally used by management researchers by involving 'members of an organization over a matter which is of genuine concern to them' (Eden and Huxham 1996, p. 75). A variety of AR approaches have developed over the years and it is difficult to pin down a precise definition of AR. However most of these approaches have some common characteristics. To help researchers appreciate the many forms of AR, Peter Reason and Hilary Bradbury published the first edition of the Handbook of Action Research in 2001.

According to the current edition of this handbook AR is defined as follows (Reason and Bradbury 2007, p. 4):

Action research is a participatory process concerned with developing practical knowledge in the pursuit of worthwhile human purposes. It seeks to bring together action and reflection, theory and practice, in participation with others, in the pursuit of practical solutions to issues of pressing concern to people, and more generally the flourishing of individual persons and their communities.

Reason and Bradbury (2007, pp. 4-5) describe the five dimensions of AR as follows:

1. It produces practical knowledge that could be applied in daily practice.

2. It often contributes to human emancipation

3. It is participative in a democratic way.

4. Process and outcomes are equally important while developing knowledge-in-action. 
5. It emerges over time as an evolutionary and development process.

Raelin (1999, p 121), who was the guest editor of a special issue of Management Learning on action research, states that AR has its 'philosophical basis in gestalt psychology, pragmatism and democracy', its 'epistemology is knowing through doing' and the methodology involves 'iterative cycles of problem defining, data collection, taking action or implementing a solution followed by further testing'.

Thus AR can be described as a process of collaborative inquiry carried out by people affected by a problem or concern, often using a cyclical process to increase their understanding of the real problem before moving towards a solution. The research process itself is emergent and responsive to the situation. AR often uses a variety of methods to converge towards a solution. People who participate in an AR process feel emancipated or liberated through the process. From this description AR seems to be somewhat fluid in nature thus drawing the criticism that it may not produce valid results that can be generalised.

Although several versions of AR are in use (Brooks and Watkins 1994; Raelin 1999; Reason and Bradbury 2007), the AR process described next in this paper was the one generally adopted by practitioners conducting academic research in the university where the research projects described here were carried out.

According to Dick (2001), both action (change) and research (understanding) are pursued conducting AR. AR incorporates critical reflection on the action to gain better understanding, which results in more informed action. AR is also usually participative and qualitative although quantitative methods have been used by some researchers when the situation demanded it.

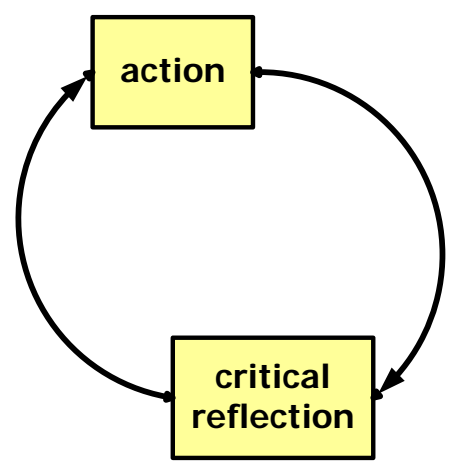

Figure 1 General model of action research

The AR cycle commonly used in the university's doctoral program is the Deakin cycle (Kemmis and McTaggart 1988) of plan-act-observe and reflect, and then the cycle repeats itself. So the researchers often start with a 'fuzzy' problem and, as they take action, observe and reflect on the situation, thus converging through iterative cycles to a better understanding of the situation. This leads to better actions. 
In AR data drives the research. Action researchers should show some scepticism about what they find in order to disconfirm the findings. The more they try to disconfirm the findings, the more rigorous the research will be. Therefore, it is quite common to find a mixture of methods being used in AR that offer different perspectives of the research problem at hand. The use of different methods also serves to triangulate the findings by helping to confirm/disconfirm the findings.

\section{Soft systems methodology}

SSM was developed through the work of researchers from Lancaster University in the 70's, who found that the methods adopted through well-established 'hard' systems approaches were inadequate to address ill-structured, complex, real-world problems faced in management situations. This led to four key ideas that resulted in the development of the first seven-step version of SSM (Checkland 1999, p. A7-8).

The four key ideas were:

1. In every situation of AR that the researchers undertook people were endeavouring to take purposeful action.

2. There were many interpretations or worldviews of a declared purpose of a system.

3. It was not possible to develop a definite model. However using a variety of models as an organized learning system helped debate and accommodate the various views about the situation.

4. Any course of action that was then arrived at through this process has to be both desirable and feasible for the people involved in the situation.

Figure 2 shows the seven-step (cluster) version of SSM that was developed through the initial work in applying systems thinking to real-world problems and presented in a paper by Checkland in 1972 in the Systems Engineering Journal. The first two stages of this model help a researcher to enter a problem situation, find out about the situation and express it. A root definition is developed in Stage 3 that enables development of conceptual models in Stage 4. A line separates stages 1 and 2 from 3 and 4 to indicate that the researcher has moved from the real world to a systems thinking world. After building conceptual models a reality check is made by moving back to the real world and assessing the feasibility and desirability of the solution arrived at through conceptual modelling in stages 5 and 6 . Action follows to improve the situation in Stage 7. The seven-step version was described in a book (Checkland 1981) that helped to teach SSM to researchers and practitioners. 


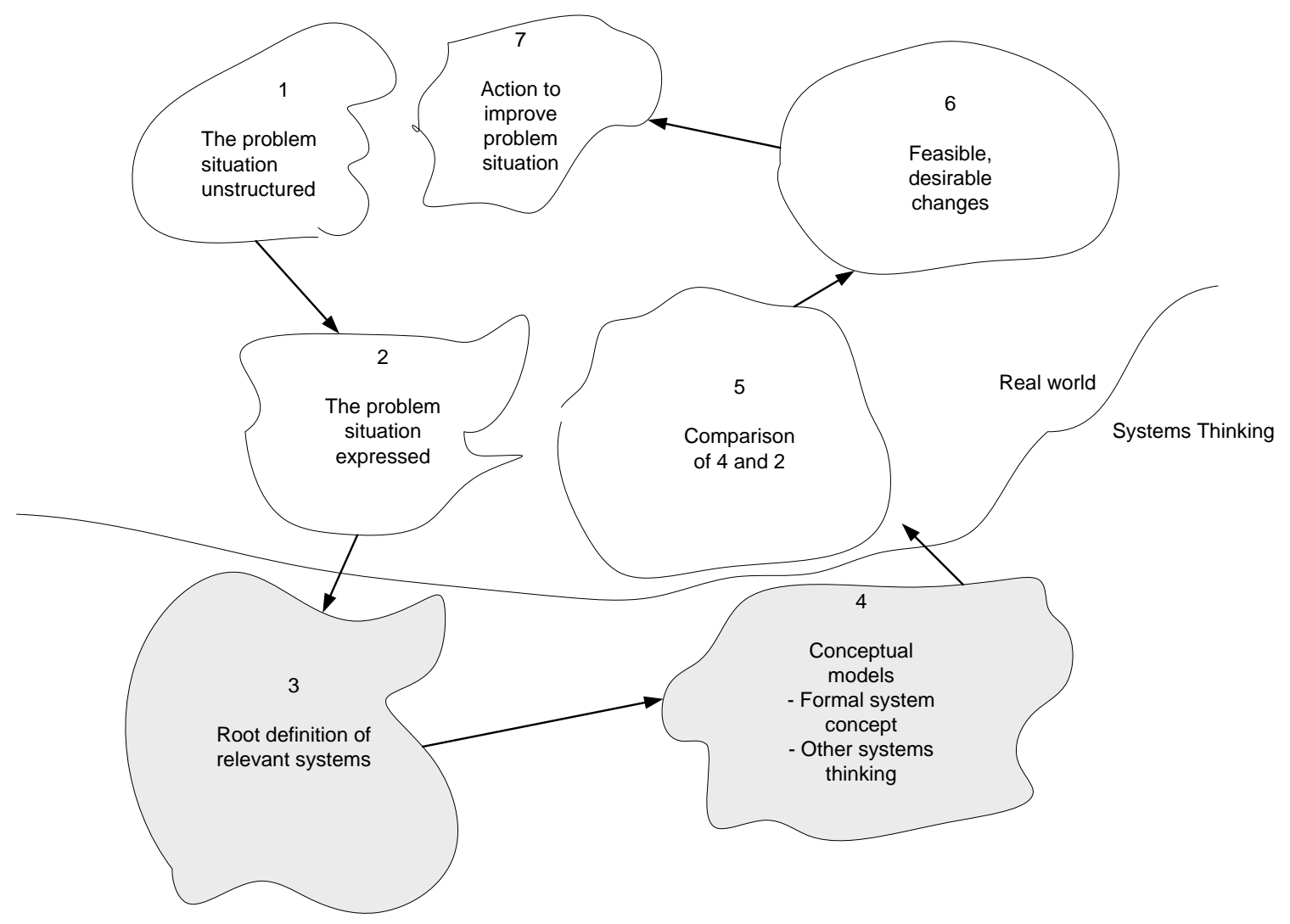

Figure 2 Seven-step version of SSM (Source: Checkland 1993, p. 163)

As SSM started being used it became clear that the process needed to be enhanced and a twostream version of SSM was developed that took into account cultural and political issues that arose while applying SSM in the real world. This model can be found in a book by Checkland and Scholes (1990) that also includes many actual applications of SSM. Figure 3 shows the two-stream or strand version (Jackson 2003, p.189). In this version, one stream, called the logical stream, followed the path of the original seven-step version. However, there was also a new stream, called the stream of cultural analysis, which included three types of analysis analysis of the intervention, social systems analysis and political systems analysis. Social analysis considers norms and values while political analysis provides information on power issues. 


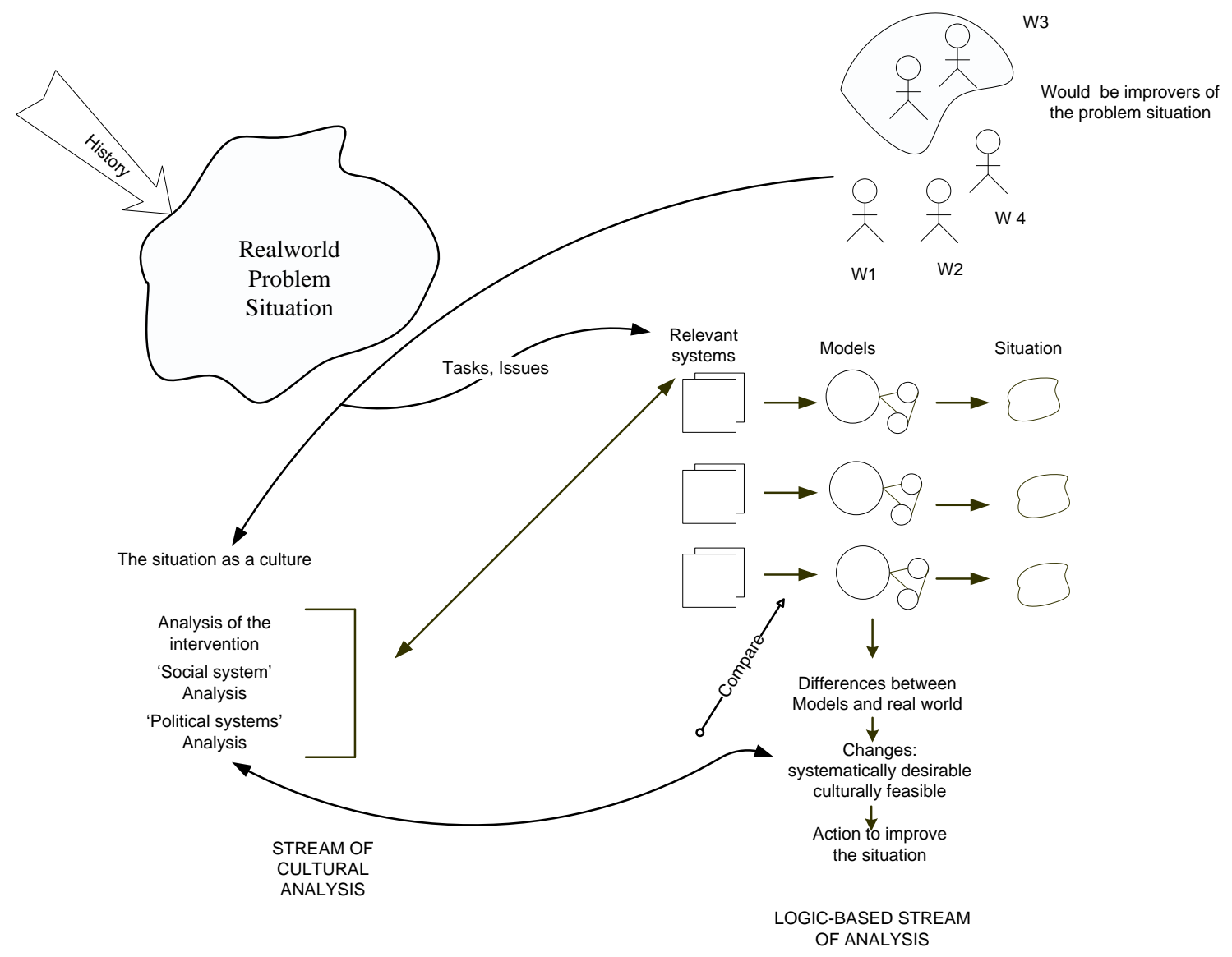

Figure 3 The two-stream version of SSM (Source: Jackson 2003, p. 189)

According to Checkland and Scholes (1990, p. 251-52), the seven-step version of SSM grew out of research conducted by university staff helping organizations outside the university to address ill-structured problems. Hence it resembled a consultancy framework where an outsider is hired to intervene in problems occurring in organizations. As SSM started being applied to day-to-day work by practitioners such as Scholes, it became a mental model for thinking about problematical situations. According to Checkland and Holwell (1998, p. 164), the former prescriptive set of seven steps to be followed in sequence came to be known as Mode 1 SSM while the latter more sophisticated way of using SSM as a sense-making device came to be known as Mode 2 SSM. Novices still tend to use Mode 1 SSM while experienced users are attracted to Mode 2 even though it is more challenging.

A recent book by Checkland and Poulter (2006 p.11) presents a basic version of SSM which includes the following activities:

1. A problematical real-world situation demanding action to improve it.

2. Creation of models of purposeful activity relevant to the situation from different worldviews

3. A process to explore the models as devices to explore the situation 
4. A structured debate about desirable and feasible changes including a discussion on power issues and considering social norms and values

5. Taking action to improve the situation.

Even though a simplified version of SSM is shown in the latest book the process of analysis includes the components described in the earlier versions.

Figure 4 shows a basic simplified process of SSM (Checkland and Poulter 2006, p. 12).

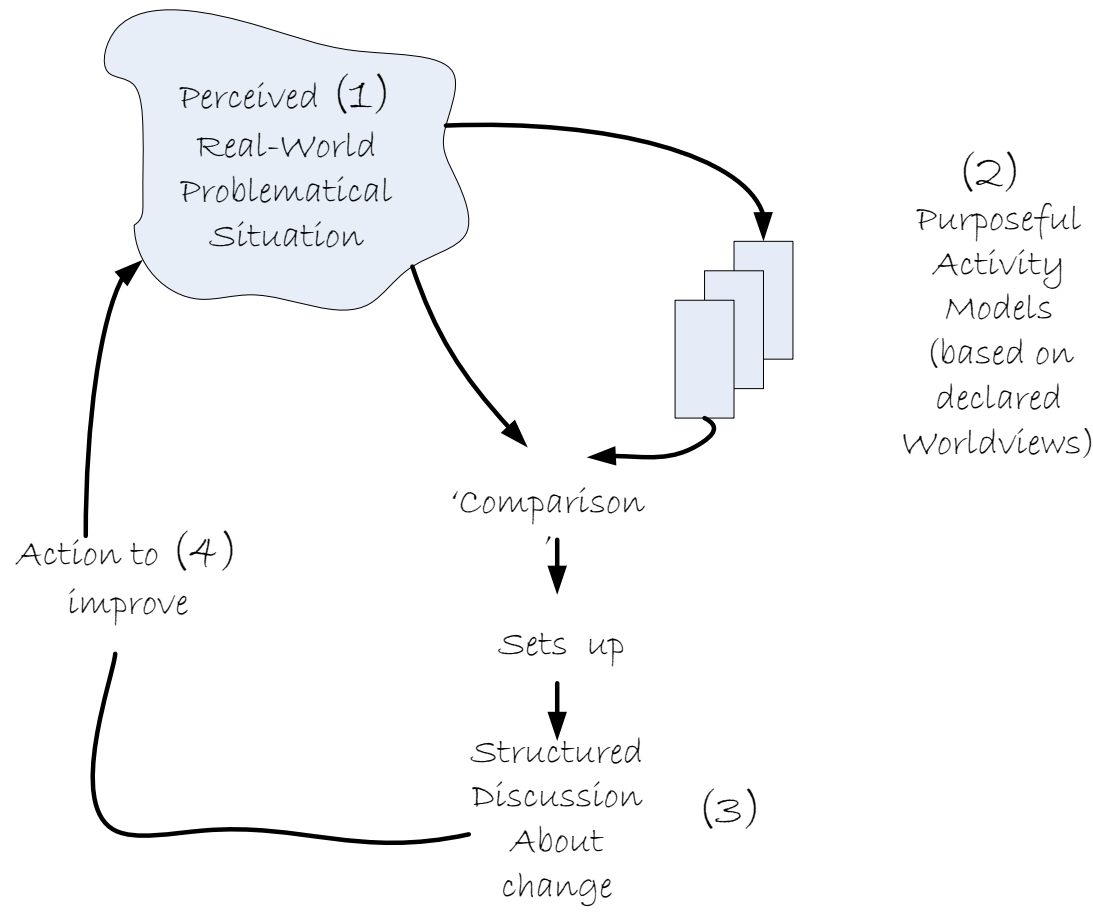

Figure 4 Basic SSM process (Source: Checkland and Poulter 2006, p 13)

The dialectical model of SSM

The doctoral researchers at the Australian university where the research reported in this paper was conducted often used a dialectical version of the SSM model proposed by Dick (2000).

This dialectic form of investigation is not a new model of SSM but presents Checkland's version from a different perspective. Dick (2000) views SSM as progressing through four dialectics:

- $1^{\text {st }}$ dialectic - Between immersion (rich picture) and essence (root definition) where researchers try and experience the problem situation as fully as possible and then stand back and define its essential features.

- $\quad 2^{\text {nd }}$ dialectic - Between the essence (root definitions) and the ideals (conceptual model) where researchers try to find an ideal way to achieve the same transformation of inputs into outputs.

- $\quad 3^{\text {rd }}$ dialectic - Between ideals and reality where researchers think about improvement to the ideals or the actual situation. 
- $\quad 4^{\text {th }}$ dialectic - Between plans and implementation where the plans are implemented and differences between plans and reality can be monitored, through which further improvements can be carried out.

Dick's proposed way of using soft systems thinking is more 'action' driven than 'concept' driven and seems to have been easier to adopt while putting soft systems thinking into practice by managers. An example of how the dialectical method is used is explained in the first case study described in this paper.

\section{Action research and systems thinking}

Greenwood and Levin (2007, p. 59) state that a 'systems approach necessarily underlies AR in all its manifestations. Both rely on an interconnected and holistic view of the world'. They add that $\mathrm{AR}$ also tries to transform society into more open systems.

The principal author of this paper has used open systems approaches, such as 'search conferences', in his own doctoral work using AR. Greenwood and Levin (2007) also advocate the use of search conferences within a pragmatic AR process. A search conference fits in with the democratization goals of AR.

Flood (2001) differentiates between systems thinking and systemic thinking by arguing that while systems thinking takes an objective stance, systemic thinking takes a subjective stance. He argues that SSM is a form of systemic thinking as reality is perceived through people's interpretation of their experiences. Flood also states that 'Action research carried out with a systemic perspective in mind promises to construct meaning that resonates strongly with our experiences within a profoundly systemic world’ (Flood 2001, p.143).

SSM and AR have a close connection as SSM itself was developed through an interpretative AR project looking into situations existing in the real world. Checkland and Holwell (1998, pp. 22-23) refer to the version of AR proposed by Argyris et al. (1982) where the crucial elements are 'a collaborative process between researchers and people in the situation; a process of critical inquiry; focus on social practice; and a deliberate process of reflective learning'. But they feel that conventional AR misses 'a desired-in-advance intellectual framework of ideas, a framework in terms of which what constitute knowledge about the situation researched will be defined and expressed'. They feel that without this framework AR might lose its rigour.

Researchers in a doctoral program conducted by Monash University (Sarah et al. 2002) have utilised systems thinking methodologies in conducting AR. The first batch of candidates who used systems thinking in their AR set up their research using the FMA (framework, methodology and action) model advocated by Checkland and Scholes (1990). They adopted the suggestion by Checkland that a desired-in-advance intellectual framework is required in AR projects. Figure 5 shows the FMA concept. 


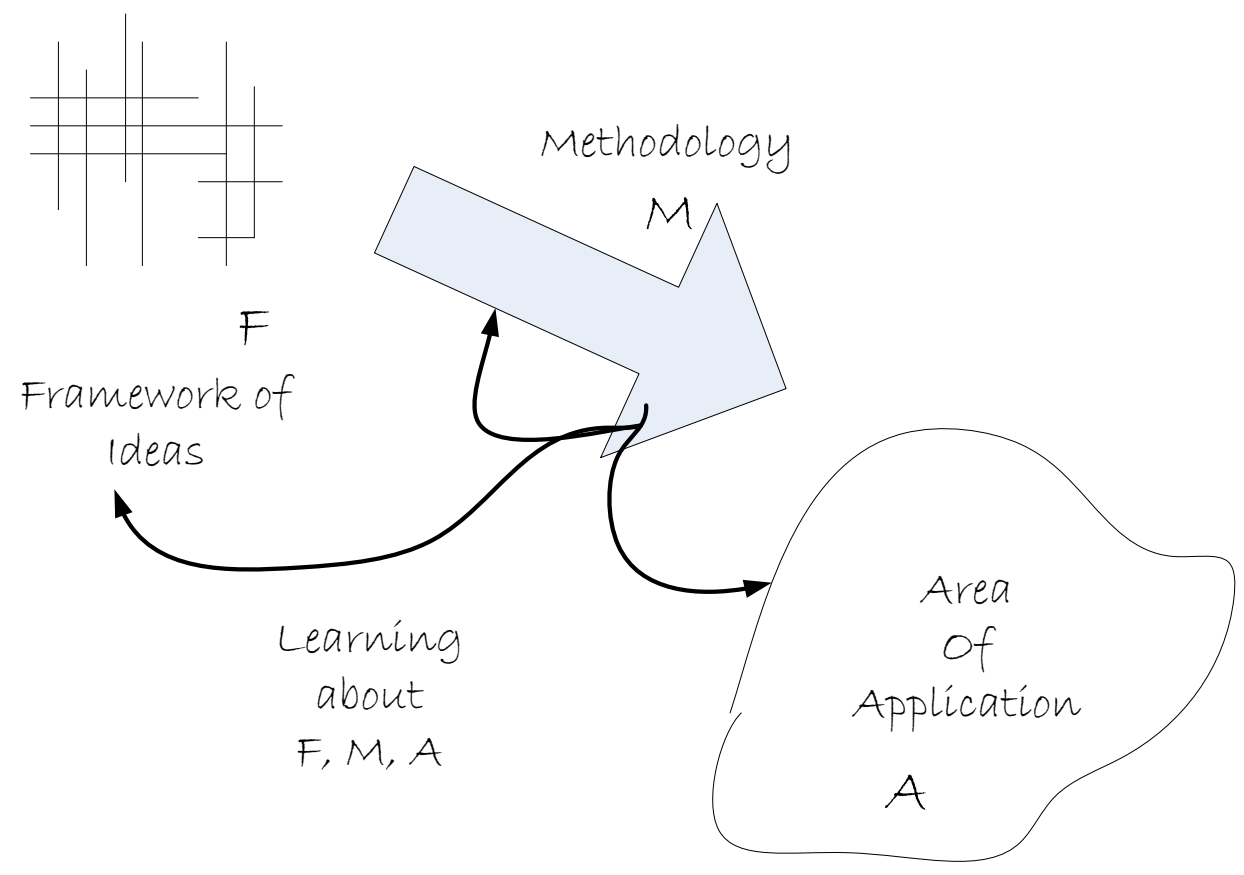

Figure 5 Elements of research (Source: Checkland 1995, p3)

Table 1 shows a comparison between a general AR process and the SSM process.

\begin{tabular}{|l|l|}
\hline \multicolumn{1}{|c|}{ SSM } & \multicolumn{1}{c|}{ AR } \\
\hline Problematical situation & Fuzzy problem \\
\hline Taking purposeful action & $\begin{array}{l}\text { Taking action to observe and reflect on the } \\
\text { situation }\end{array}$ \\
\hline Strategic questioning & Questioning as part of the reflective process \\
\hline Participatory & Mostly participatory \\
\hline Taking into account people affected & Empowerment \\
\hline
\end{tabular}

Table 1 Comparing SSM and AR

The main difference seems to be that SSM advocates the use of a declared-in-advance intellectual framework while AR may not always take this approach. There are also other administrative reasons why such a framework would be useful to doctoral researchers in academia which are explored in the next section of this paper.

AR and SSM for academic research

Although systems thinking and AR go hand in hand there are some limitations in applying SSM in management research where a solution is expected from the research. Checkland and Winter (2006, p.1435) state that SSM is a 'methodology that provides a set of principles for intervening in human problem situations in order to bring about what would be judged to be "improvements"'. If the aim of practitioner research is to make the practitioner into a better researcher then processes such as SSM would be very helpful. However, when the aim of the 
research is to find solutions or develop a product questions could be raised as to the effectiveness of a process such as SSM or AR. Another issue that is often faced by researchers using AR and SSM is when does one stop? One can go on learning endlessly with these methodologies. When these are adopted to do a doctoral thesis there are time and resource constraints limiting the duration of the project. This issue is out of the scope of this paper but has been discussed in detail by West and Stansfield (2001). Their paper also shows how structuring AR projects using the FMA model is useful in many respects.

When research is conducted for academic purposes it is mandatory to seek ethics approval for the research. In these situations a declared-in-advance framework would be very useful to help in the approval of AR as the research methodology. It also helps candidates who are often required to declare details of their methodology in universities which often use the scientific model of research administration. In the university where the principal researcher is now situated the doctoral assessment process which acts as a gateway to confirm candidature would pose significant problems to candidates who use AR in more flexible ways.

\section{Case 1 : A diagnostic expert system (DES) for an industrial environment}

This project was carried out by the Technical Director of a Research and Development firm in Singapore for a $\mathrm{PhD}$ program (Tay 2003). The project involved the development of a diagnostic expert system (DES) for military vehicles that changed the way in which the software development firm designed and implemented software solutions for its customers.

\section{Thematic concern}

The primary intention of this study was to solve logic faults that were occurring when the modelling software was being developed. The three primary questions that were proposed to address the thematic concern of the research were:

- How to derive an (effective) inquiry process (to carry out the modelling)?

- How to refine the modelling techniques used?

- How to detect missing content?

\section{Choosing action research}

AR was selected as the research methodology as the researcher wanted to pursue action outcomes and research outcomes at the same time to address a problem that was a real concern to his firm. The project required active participation of designers and modellers developing the system, making AR useful. Due to its responsive nature AR also helped in the generation of situation-specific knowledge. AR helped keep the project on schedule as project work and research work could be carried out simultaneously. The researcher used AR as a meta-methodology to embed other methodologies that helped in the investigation. SSM was one such methodology used.

Figure 6 shows the dialectic nature of AR moving between 'thought' and 'action' while going through the AR cycle of planning, acting, observing and reflecting. 


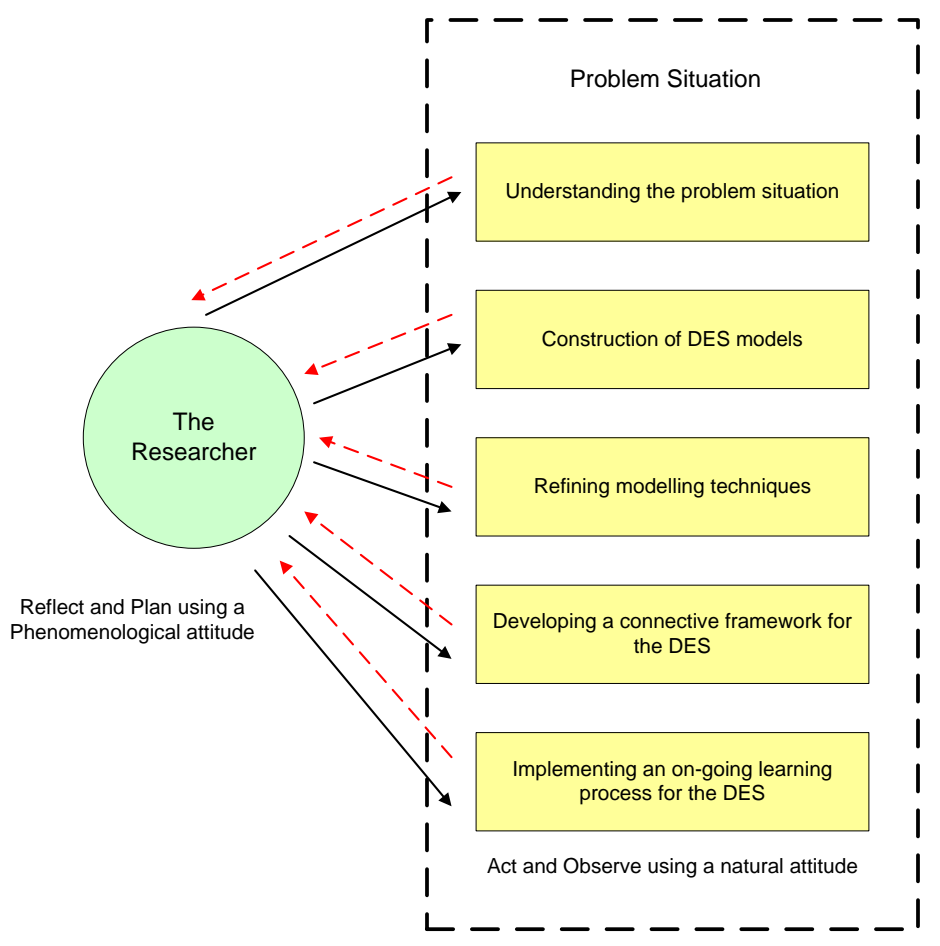

Figure 6 Dialectic nature of AR used in the research (Tay 2003, p87)

\section{Incorporating SSM}

SSM was used in this research as an initial approach to understand the problem situation based on the work of Wilson (1984), Checkland and Scholes (1990) and Checkland (1999). Initially, the seven-step version proposed by Checkland (1993, p. 163) was used to set up the investigation. Some setbacks (described later) were encountered, and an inquiry process using Dick's version of Checkland's SSM was designed to fit the investigation (Dick and Swepson 1994; Dick 1993; Dick 2000), resulting in a four-stage DES. A trial was carried out using the four-stage DES inquiry process. This process was then applied to several vehicles for which the diagnostic systems were required. Figure 7 shows how the inquiry process developed through two AR cycles. 


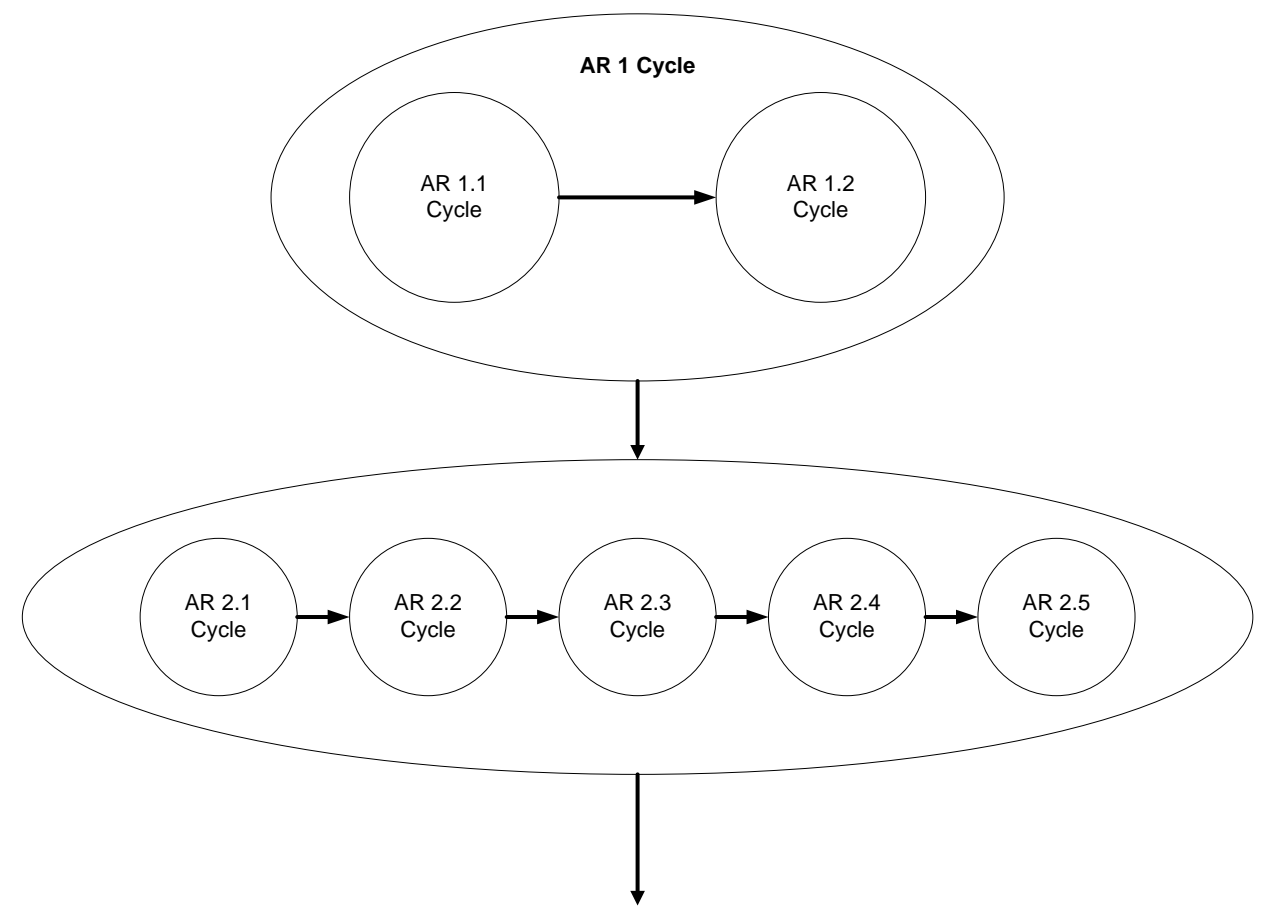

\section{Cycle Activity}

AR 1 Understanding the problem situation

AR 1.1 Applying Checkland's SSM

AR 1.2 Analysing setbacks in using Checkland's SSM

AR 2 Constructing DES models

AR 2.1 Deriving four-stage DES inquiry process using Dick's version of Checkland's SSM

AR 2.2 Adopting Reliability-Centred Management as the content guideline

AR 2.3 Using Jung's psychological types as decision-making preferences

AR 2.4 Trialling the four-stage DES inquiry process

AR 2.5. Refining the diagnostic models for a new vehicle after using the model for three more vehicles

Figure 7 The first two AR cycles (Tay 2003, p 99)

\section{Results from applying a structured SSM process}

The justification for adopting an SSM model was based on Curtis and Cobham's (2002) five (philosophical) assumptions for its use. SSM is useful to deal with problems that are not 'out there'. Thus, when one of the modellers started developing the diagnostic model his main problem was that different people associated with the diagnosis had their own views about what the model should be doing. Secondly, the solution to the problem to be modelled had to be intellectual constructs. Thirdly, the problem was not a single problem but a set of interrelated problems. Fourthly, a detailed analysis was required prior to making any decisions on how the systems were to be modelled. Finally, the modeller could not be divorced from the system or its participants. The modeller had to work in collaboration with others. 
Although Checkland (1999, p. A15) states that the seven-step version is somewhat rigid and does not allow a more flexible use of SSM, the researcher was new to the concept of SSM and followed the modified seven-step model (Checkland and Scholes 1990, p. 29) which was easy to understand. A rich picture representing the problem was created to stimulate understanding of the problem situation. Using the CATWOE mnemonic (Customers, Actors, Weltanshauung (worldview), Transformation, Ownership and Environmental constraints) a root definition was formulated. At this stage, the researcher carried out a role analysis, social system analysis and political analysis. The role analysis clarified the roles of the client, problem solver and problem owner. The social analysis established the norms and values. The political analysis identified formal authority, intellectual authority, personal charisma (or lack of) and reputation. Based on the problem analysis three conceptual models were developed. The models developed later included control structures to meet the criteria of efficacy and efficiency. Two reviews were conducted with the modeller with the conceptual model. During the first review it became evident that the modeller was still lacking information and this was attributed to his inability to persuade team members of the project to provide the required information. A second review with the modelling team suggested further issues but a third review indicated that the team had started working well together. Unfortunately for the modeller, the client rejected his solution as they felt that the proposed model did not match the actual vehicle. This resulted in the modeller feeling demoralised and leaving the organization.

This experience caused the researcher to reflect on the setback and he realized that there was a lack of a declared-in-advance intellectual framework of ideas suggested in the SSM process (Checkland and Holwell 1998). Such a framework was needed to define and express what could be construed as knowledge about the situation. While the reviews of the work using the seven-step model helped in improving teamwork it failed to address the real problem resulting in the client's rejection of the model.

Based on this analysis, a set of criteria for evaluating the effectiveness of the inquiry process was established. These included:

- Frequent visits to the physical situation (the vehicle) to ensure that any important features were not missed.

- One or more 'wholeness' purposes - One wholeness purpose was insufficient to capture the situation completely. For example, the focus on teamwork had diverted the attention of the team from building an accurate model.

- Achieve a shared sense of understanding and familiarity especially when modellers and designers were working in teams.

- Frequent review and verifications to establish coherence among team members and the client (stakeholders).

\section{Developing a four-stage DES process}

Dick and Swepson (1994) and Dick (1993, 2000) take a different approach to SSM by progressing through four dialectics. The dialectics have a win-win intent to focus on 
disagreements with a view to turn them into agreements. The researcher then developed a fourstage inquiry model based on Dick’s dialectic SSM process as shown in Figure 8.

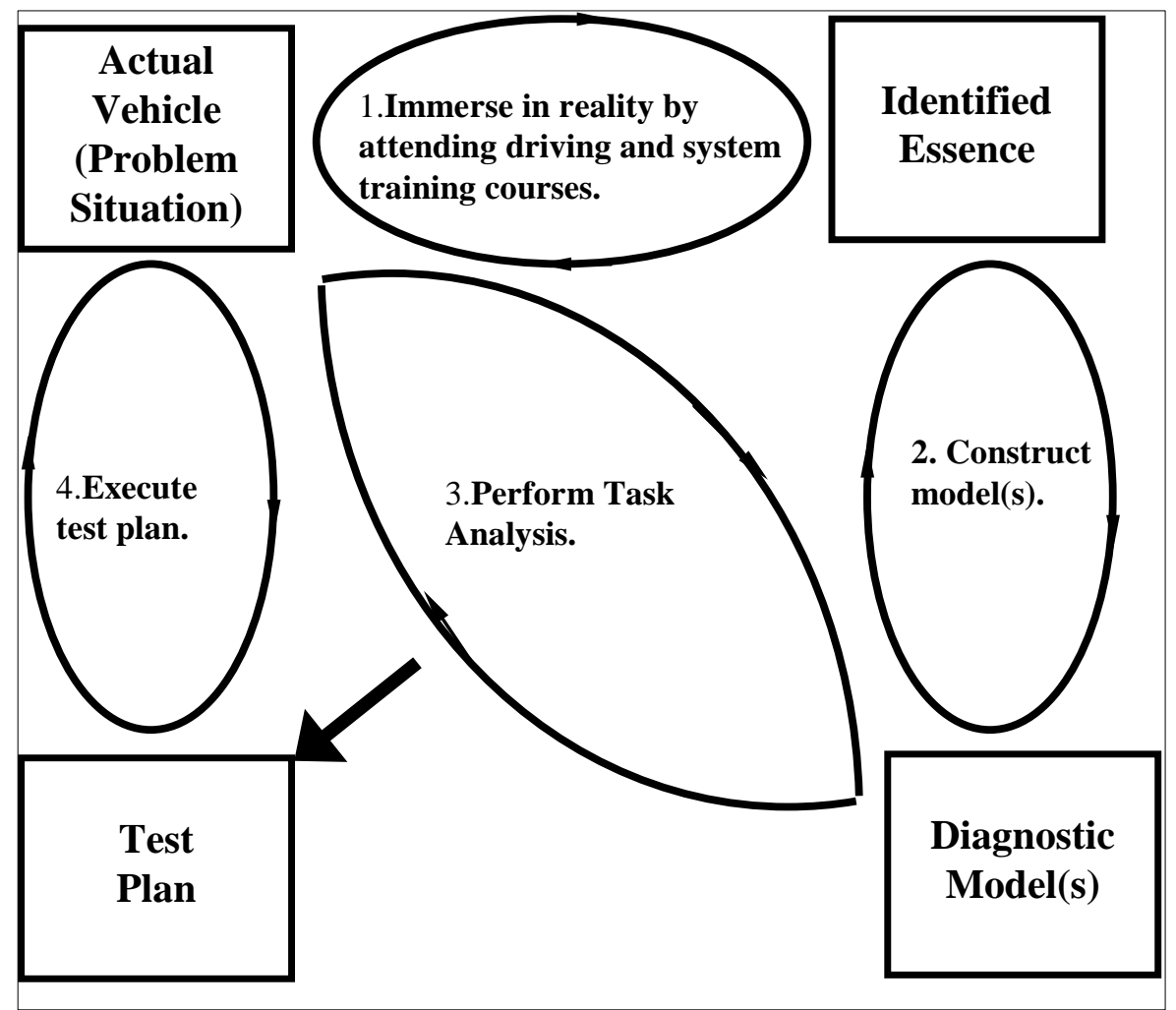

Figure 8 The four-stage DES inquiry process (Tay 2003, p114)

In the first AR cycle the modeller was immersed in the problem situation. This was done by attending driving and maintenance courses for the vehicle. This helped the modeller to capture the essence of the vehicle and its various operations.

In the second cycle the modeller constructed a DES for a specific vehicle operation. This is the dialectic between the essence of the vehicle and the model. The modeller is encouraged to forget about the vehicle and focus on the derivation of the DES model.

In the third cycle the modeller performs task analysis - analysing how people do a task, how they act and what things they need to know. This is the dialectic between the constructed DES model and the real vehicle. This cycle is repeated until all the mandatory inspection and repair tasks are completed.

In the final cycle the test plan is verified against the real vehicle. Differences are noted and addressed. This is the dialectic between the test plan and the real vehicle. 
The DES inquiry process developed through this research was successfully used for modelling an armoured recovery vehicle, a military truck and an armoured carrier. It was also used to refine models previously constructed by the organization for an armoured fighting vehicle.

The DES inquiry process helped the organization develop an effective inquiry process and eliminate missing content in the models. It also revised the way in which models were developed for future projects.

\section{Case 2: An electronic health knowledge management system (EKMS)}

This project was carried out for a District Health Board in New Zealand to implement a series of electronic health knowledge management systems (Orr 2006). The objective of the project was to increase the capacity of the Board to bring together and have clinical information from multiple distributed resources to provide better integrated care and health outcomes. It included implementing several interrelated projects:

1. A single login interface from which all key individual patient demographic information, investigation results, clinical documents and referrals, past treatment events and warnings could be viewed.

2. A patient tracking system for emergency care providing real-time information on a patient's location, investigation and treatment status.

3. An electronic medical document repository including the migration of a large number of historical clinical documents.

4. Electronic clinical audit facilities focusing first on surgery and helping the provision of clinical outcome measures.

5. Referral status messaging and electronic discharge summaries enhancing real-time information sharing across primary and secondary care environments.

\section{Thematic concern}

The main aim of the research was to use an AR process of planning, acting and critical reflection to develop conceptual models to enhance the implementation of Information and Communications Technology (ICT) based health knowledge management systems. While New Zealand has one of the highest rates of ICT-enabled healthcare provision it has also experienced significant project failures. Therefore, one of the reasons for adopting a different process to implement the ICT systems was the belief that the process developed through this research would help in implementing successful technology-based healthcare projects.

\section{Choosing AR}

The research was carried out in teams using an AR and reflective learning approach. AR was selected as the methodology due its focus on change and learning, its qualitative, exploratory and theory-building nature, its emancipatory emphasis, its capacity to accommodate researcher participation and its responsiveness and flexibility in complex changing situations (Dick 2001; Reason 2006). 


\section{Relevance to SSM}

Although SSM was not explicitly used as a methodology within AR in this thesis, a number of parallels between Checkland's evolving understanding and development of his own work and the researcher's conceptualisation of the research process using mnemonics and a conceptreality gap model were observed. Thus SSM was used in the sense-making mode (Mode 2) in this research.

The researcher is a psychiatrist by profession and recorded the parallels between Checkland's 30 years of development of SSM and the essence of psychotherapeutic practice in one of his papers that formed part of his thesis (Orr and Sankaran 2007).

During the initial stages of his research the researcher was under the impression that the focus of his AR would be to resolve some technical integration and configuration issues. He also thought that a structured use of the seven-step version would support the initial focus of the research. The researcher's initial expectation was that AR would form the key project stages and would somehow be separated from the daily work of the project. However, as the research progressed, the focus of the AR narrowed to deal with psychological process issues and capability development, and AR became integrated with the daily fabric of the project to aid reflective practice.

As the researcher read the works describing the development of SSM (Checkland 1999, 2000a, 2000b, 2005, 2006) he felt that the broad approach that he and his team took embraced many of the principles that Checkland now identifies as the essence of SSM.

In particular, the researcher points to two observations from the paper by Checkland and Winter (2006, p. 1435):

- That SSM provides a set of principles for intervening in human problem situations in order to bring about improvement.

- SSM is relevant to both the content of the perceived situation (SSMc) and the process dealing with that content (SSMp)

According to the researcher, these two statements echo the essence of psychotherapeutic practice.

Checkland's SSM evolved to focus on human dynamics, relations, needs, aspirations, perceptions and assumptions to bring about group accommodation of a process. By using the iterative creation of shared models relative to their perceived and current reality, SSM facilitates improvement of the situation or world they live in.

Psychotherapeutic practice has similar aims by intervening in human situations to bring about positive change. The goal of the practice is to form an empowering therapeutic alliance that seeks to understand, accept and meet the patient, client or group where they are in terms of their worldview. A key goal of psychotherapy is to help build an agreed model about the factors 
that have led the person or group presenting in this way, at this time, including identified strengths. This helps to build an agreed plan of required action to move forward which takes into account what is feasible and what is desirable, perceived priorities, preferences and cultural values aiming to minimise weaknesses or vulnerabilities and build on strengths, maximise empowerment, motivation and self-efficacy, weighing risks and benefits and recognising potential conflicts and interests. This is an iterative process that has many similarities to the principles of SSM.

The reality-concept gap model that resulted from this research, shown in Figure 8, is an example of building a conceptual model to support the AR process. In fact, it could be considered the language framework used for this research supported by the SAFE (Scalable Affordable Flexible Equitable) mnemonic . Figure 9 shows the concept-reality gap model.

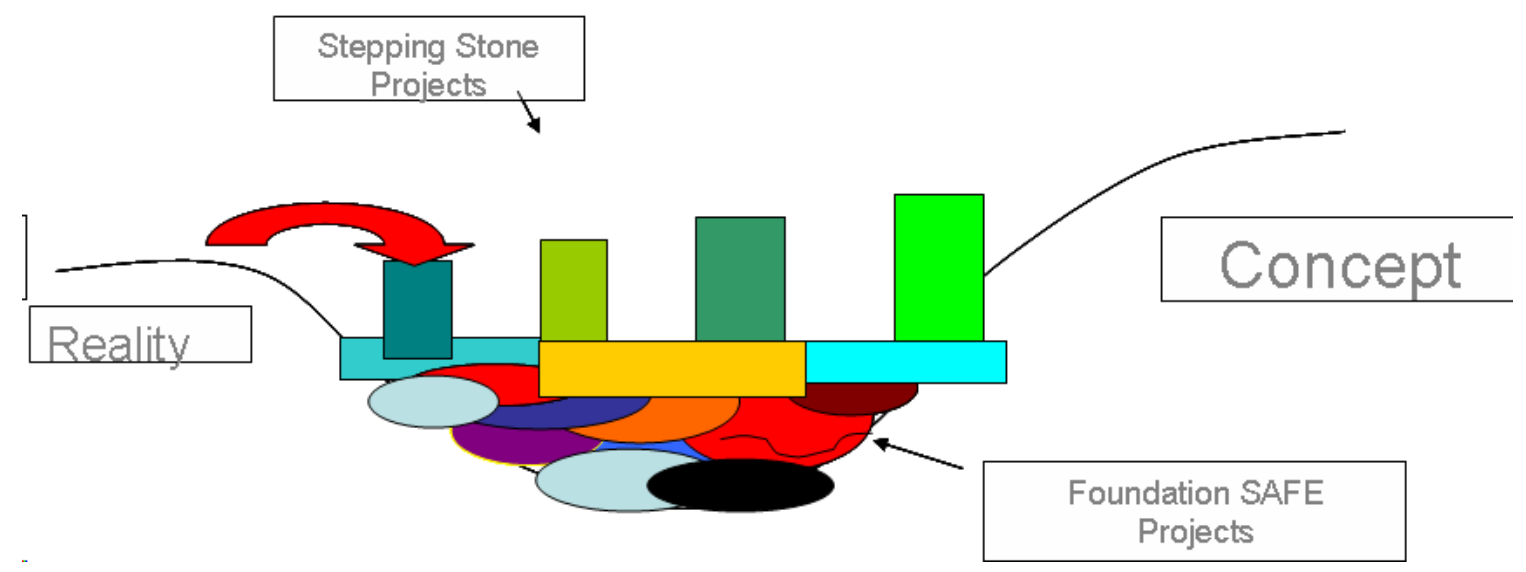

Figure 9 Reality - Concept Gap (Orr 2006, p109)

During the AR cycles used to implement the electronic health knowledge management system a central metaphor used throughout the project was the concept-reality gap. This resulted from a visual representation that when an individual or system faces a stressor or change there may be an initial drop in the functioning before a hopeful reorganisation, improved resilience and capability to return to the baseline. This phenomenon can be observed in concepts such as the reengineering curve, the death valley of change, crossing the quality chasm or moving through a grief process (Committee for Quality of Healthcare 2001; Elrod and Tippett 2002; Kelly and Tucci 2001).

While an initial drop in performance may be acceptable in a business process reengineering process with a belief that it will lead to increased productivity, it may be detrimental to patient safety in a healthcare situation. This may result in the abandonment of the new process to return to the original trusted process. Failure to appreciate the magnitude of this 'acceptance' gap could lead to full or partial failure of ICT implementation in a healthcare system (Glouberman and Mintzberg 1996; Heeks et al. 1999; Orr 2000). 
While it is possible to jump from reality to concept in one go, this might result in a crash-andburn situation in a healthcare scenario. Therefore, an incremental process is needed to move from reality to concept using a stepping stone approach as shown in Figure 9. But the stones need a firm foundation and this was provided in the research through the use of mnemonics such as SAFE projects. The combination of a metaphor and a mnemonic was very useful to implement the change processes required in this project. Using AR cycles helped to support the incremental nature of the implementation.

\section{Discussion}

The two research projects described in this paper used SSM in different ways. The first project, which was carried out by a systems engineer, took a different view of applying systems thinking to software development. However, the researcher was essentially looking for a solution to minimise the number of logic faults occurring in a modelling process. The application of SSM helped not only in solving his problem, but also contributed to better practice- the dialectic model of SSM he adopted resulted in a process of ongoing learning in his practice. Thus, it also fulfilled the aims of SSM being a learning process in human activity systems.

However, it was evident that the lack of an intellectual framework resulted in initial setbacks with the modelling and the development of a four-stage DES inquiry process which served as the intellectual framework. Applying SSM in the second round helped to structure the research better.

The second project carried out by a psychiatrist did not directly include SSM but recognised parallels between SSM and his own practice. SSM became a sense-making system. One can say that there are philosophical similarities between SSM and AR as applied in a therapeutic practice environment. It is interesting that the researcher first thought of SSM as a process to implement an information systems project but later realised that it is a process that promotes better understanding. SSM, like AR, can also be used as a meta-methodology to help thinking about the research problem and gain better understanding before other methods are adopted. Unlike the first case study the 'reality-concept' gap could be considered as the declared-inadvance or developed framework that guided this research.

\section{Conclusions}

Although there are many similarities between the principles of AR and soft systems thinking the process of inquiry using these approaches might take a long time and may not be goal seeking. However, incorporating systems thinking approaches, such as search conferences or SSM can be powerful when they are used in an AR project to improve researchers' practice, enable stakeholder buy-in for the changes being proposed as a result of the AR intervention and incorporate a declared-in-advance framework of ideas to pursue AR more effectively. Some more practical versions of SSM, such as the dialectical model described in the expert systems project, could help researchers use a systems approach more effectively towards achieving a solution in an AR project. The FMA concept to undertake any research advocated by Checkland could come in handy for action researchers to structure their research. This has 
some advantages while using AR as a methodology for academic research, where the university's human research ethics approval process and research progress measurement systems require a more precise account of what the researcher actually plans to do during the research.

\section{References}

Argyris, C., Putnam, R. and Mclain Smith, D. (1982), Action Science: Concepts, Methods and Skills for Research and Intervention, Jossey-Bass, San Francisco, CA.

Brooks, A. and Watkins, K.F. (1994), The Emerging Power of Action Inquiry Technologies, Jossey-Bass, San Francisco, CA.

Checkland, P. (1972), “Towards a system-based methodology for real-world problem solving, Journal of System Engineering, Vol 3 No. 2. published also in Beishon, J. \& Peters,G. (Eds.), Systems Behaviour, Harper \& Row, London, pp. 51-77.

Checkland, P. (1981), Systems Thinking, Systems Practice, John Wiley, Chichester.

Checkland, P. (1993), Systems Thinking, Systems Practice, John Wiley, Reprinted with corrections, Chichester.

Checkland, P. (1995), "Soft systems methodology and its relevance to the development of information systems”, in Stowell, F.A. (Ed.) Information Systems Provision: The Contribution of Soft Systems Methodology, McGraw Hill, London, pp. 1-15.

Checkland, P. (1999), Soft Systems Methodology: A 30-year Retrospective, John Wiley, Chichester.

Checkland, P. (2000a), "The emergent properties of SSM in use: A symposium by reflective practitioners”, Systemic Practice and Action Research, Vol. 13 No. 6, pp. 799-823.

Checkland, P. (2000b), "New maps of knowledge and some animadversions (friendly) on science (reductionist) social science (hermeneutic), research (unmanageable) and universities (unmanaged)", Systems Research and Behavioural Science, Vol 17 No. S1, pp. S59-S75.

Checkland, P. (2005), "Webs of significance: The work of Geoffrey Vickers”, Systems Research and Behavioural Science, Vol. 22 No. 4, pp. 285-90.

Checkland, P. (2006), "Reply to Eden and Ackermann: The future of problem structuring methods?”, The Journal of Operational Research Society, Vol. 57 No. 7, pp. 769771.

Checkland, P. and Holwell, S. (1998), Information, Systems and Information Systems: Making Sense of the Field, John Wiley, Chichester.

Checkland P. and Poulter, J. (2006). Learning for Action: A Short Definitive Account of Soft Systems Methodology and its Use for Practitioners, Teachers and Students, John Wiley, Chichester.

Checkland, P. and Scholes, J. (1990). Soft Systems Methodology in Action, John Wiley, Chichester.

Checkland, P. and Winter, M. (2006). "Process and content: Two ways of using SSM", The Journal of the Operational Research Society, Vol. 57 No. 1, pp. 1435-41.

Cicmil, S., Williams, T., Thomas, J. and Hodgson, D. (2006), "Rethinking project Management: Researching the actuality of projects”, International Journal of Project Management, Vol. 24, pp. 675-686. 
Committee on Quality of Healthcare in America (2001). Crossing the Quality Chasm: A New Health System for the $21^{\text {st }}$ Century, National Academy Press, Washington DC.

Curtis, G. and Cobham, D. (2002). Business Information Systems: Analysis, Design and Practice, $4^{\text {th }}$ edn., Pearson, Essex.

Dick, B. (1993). You Want to Do an Action Research Thesis?, [Online], http://www.scu.edu.au/schools/gcm/ar/art/arthesis.html.

Dick, B. (2000). Soft Systems Methodology. Session 13 of Areol-Action Research and Evaluation Online, [Online], http:/www.scu.edu.au/schools/gcm/ar/areol/areolsession13.html.

Dick, B. (2001). “Action research: action and research”, in Sankaran, S., Dick, B., Passfield, R. and Swepson, P., (eds.) Effective Change Management Using Action Learning and Action Research, Southern Cross University Press, Lismore, pp. 21-27.

Dick, B. and Swepson, P. (1994). Appropriate Validity and its Attainment Within Action Research: An Illustration Using Soft Systems Methodology, [Online], http:/www.scu.edu.au/schools/gcm/ar/arp/sofsys2.html.

Eden, C. \& Huxham, C. (1996). “Action research for management research”, British Journal of Management, Vol 7 No. 75 pp. 75-86.

Elrod, P. and Tippet, D. (2002). “The death valley of change”, Journal of Organisational Change and Management, Vol. 15 No. 3, pp. 273-291.

Flood, R.L. (2001). 'The relationship between 'systems thinking' to action research” in Reason, P. \& Bradbury, H. (eds.) The Handbook of Action Research, Sage, London, pp. 133134.

Glouberman, S. and Mintzberg, H. (1996). "Managing the care of health and the cure of disease. Part 1: Differentiation”, Healthcare Management Review, Vol. 26 No. 1, pp. 56-59.

Greenwood, D. and Levin, M. (2007). Introduction to Action Research: Social Research for Social Change, $2^{\text {nd }}$ edn. Sage, Thousand Oaks, CA.

Heeks, R., Mundy, D. and Salazar, A. (1999). "Why healthcare information systems succeed or fail ?”, Information Systems for Public Sector Management, Working paper series, Paper No. 9, Institute for Development Policy and Management, Manchester, UK.

Jackson, M.C. (2003) Systems Thinking: Creative Holism for Managers, John Wiley, Chichester.

Kelly, M.A. and Tucci, J.M. (2001). "Bridging the quality chasm”, British Management Journal, Vol. 32, pp. 61-62.

Kemmis, S. and McTaggart, R. (1988). The Action Research Planner, $3^{\text {rd }}$. edn., Deakin University, Geelong, Vic.

Lewin, K. (1946). “Action research and minority problems”, Vol. 2 No. 4, pp. 34-46.

Orr, M. (2000). Implementation of Health Information Systems, MBA Dissertation, Southern Cross University, Lismore, NSW.

Orr, M. (2006). The Implementation of Electronic Health Knowledge Management Systems, DBA Thesis, Southern Cross University, Lismore, NSW. 
Orr, M. and Sankaran, S. (2007). "Mutual empathy, ambiguity, and the implementation of electronic knowledge management within the complex health system, Emergence: Complexity and Organization, Vol. 9 No. 1-2, pp. 41-52.

Raelin, J.A. (1999). "Preface: Special issue”, Management Learning, Vol. 30 No. 2, pp. 11525.

Reason, P. (2006). “Choice and quality in action research practice”, Journal of Management Inquiry, Vol. 1 No. 2, pp. 187-203.

Reason, P. and Bradbury, H. (2007). Handbook of Action Research: Participatory Inquiry and Practice, $2^{\text {nd }}$. edn., Sage, London.

Sarah, R., Haslett, T., Molineux, J., Olsen, J., Stephens, J., Tepe, S. and Walker, B. "Business action research in practice- A strategic conversation about conducting action research in business organizations”, Systemic Practice and Action Research, Vol. 15 No. 6, pp. 535-546.

Sankaran, S., Hase, S. Dick, B. and Davies, A. (2006). "Reflections on developing an offshore action research/learning-based $\mathrm{PhD}$ program”, Action Learning: Research and Practice, Vol. 3 No. 2, pp. 1-15.

Tay, B.H. (2003). Using Action Research to Develop a Social Technical Diagnostic Expert System for an Industrial Environment, PhD Thesis, Southern Cross University, Lismore, NSW.

West, D. and Stansfield, M.H. (2001). "Structuring action and reflection in information systems action research studies using Checkland's FMA model”, Systemic Practice and Action Research, Vol. 14 No. 3, pp. 251-281.

Wilson, B. (1984). Systems: Concepts, Methodologies and Applications, John Wiley: Chichester. 